\title{
One dimensional capacitive loading in a frequency selective surface for low profile antenna applications
}

\author{
David Cure* and Thomas Weller \\ Dept. of Electrical Engineering \\ University Of South Florida \\ Tampa, FL, 33620 \\ E-mail: dcure@mail.usf.edu
}

\author{
Félix Miranda \\ Antenna and Optical Systems Branch \\ NASA John H. Glenn Research \\ Cleveland, $\mathrm{OH} 44135$
}

\author{
Paul Herzig \\ Engineering \& Research \\ Raytheon Systems \\ St. Petersburg, FL, USA
}

\begin{abstract}
In this paper, the impact of adding discrete capacitive loading along one dimension of a frequency selective surface for low profile antenna applications is presented for the first time. The measured data demonstrates comparable performance between a non-loaded and a capacitively-loaded FSS with a significant reduction in the number of cells and/or cell geometry size. Additionally, the provision of discrete capacitive loads reduces the FSS susceptibility to fabrication tolerances based on placement of a fixed grid capacitance. The bandwidth increased from $1.8 \%$ to $7.3 \%$ for a total antenna thickness of $\sim \lambda / 22$, and from $1.5 \%$ to $9.2 \%$ for a thickness of $\sim \lambda / \mathbf{4 0}$. The total antenna area for each case was reduced by $55 \%$ and $12 \%$, respectively.
\end{abstract}

Keywords-Frequency Selective Surface; High Impedance Surface; Low Profile Antennas; Area Reduction; Square Patches; Capacitive loading

\section{INTRODUCTION}

Herein an end loaded planar open sleeve dipole (ELPOSD) antenna backed with a square patch (SP) frequency selective surface (FSS) with discrete capacitive loading in one dimension is presented (Fig. 1). Previous works have demonstrated that dipole-type antennas above FSS ground planes tend to be narrowband [1], [2]. In [2] it was shown via simulation that the bandwidth can be increased by positioning the dipole in free space above the FSS; the typical bandwidth with this approach is $4.3 \%$ for a total antenna and FSS thickness of $\sim \lambda / 25$. The primary objective of this effort is to study the impact on antenna bandwidth and planar size when capacitive loading is introduced into the FSS. This work builds upon the design presented by Cure[1] with the goal of achieving bandwidths on the order of $10 \%$.

The capacitive loading, realized using 0603 surface mount multi-layer capacitors, provides several design advantages. For example, with the lumped capacitors located between the unit cells of the FSS a reduction in phase velocity is achieved [3], thereby enabling miniaturization of the grid and/or unit cell. There are also different options in terms of the pattern used for locating the capacitors. In this case, the direction parallel to the dipole axis was selected because it is the dominant direction of the current flow of the antenna. Concomitantly, it was decided not to use capacitors in the other direction in order to reduce the total number of elements. Also, it is conceivable that a dual-band FSS impedance response could be achieved by varying the value of the lumped capacitors. Finally, the design provides a basis for implementing frequency tuning of the FSS response by replacing the fixed capacitors with variable reactance devices (e.g. semiconductor or ferroelectric varactors).

Another important characteristic of the presented design is the use of square patches without vias in the FSS. For certain applications (e.g., mobile devices, aircraft fuselage, missile nose cone, vehicles, space suits, etc.) it is necessary to use conformal antennas, which may require the use of substrate configurations that are not amenable to thru-layer interconnects. Thus, it is desirable to design without vias in order to minimize the fabrication complexity and facilitate the use of flexible constructs.

To the best of the authors' knowledge this is the first investigation of onedimensional, discrete capacitive-loading of an FSS for antenna applications. In the following sections, the design and fabrication of antennas on two

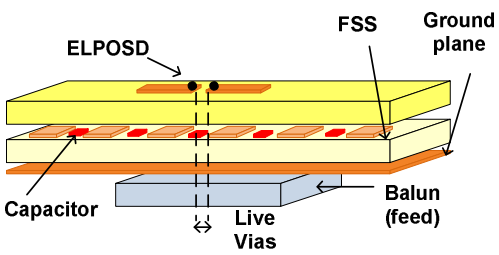

Figure 1. Multi-layer substrate with feed layer, FSS layer and dipole. substrate thicknesses are presented, along with an analysis of the FSS bandwidth characteristics based on simulated and experimental data. All simulation results shown herein were obtained using Ansoft HFSS.

\section{ANTENNA DESIGN}

Frequency selective surfaces are more narrowband as the frequency decreases [4], [5]. To achieve larger bandwidths one solution is to increase the substrate thickness [5], [6]. When this is done, greater miniaturization of the unit cell and higher surface impedance values are achieved. An important trade off, however, is the relation between bandwidth and flexibility. An increment in the substrate thickness $h$ has an impact in the flexibility, as the stiffness is directly proportional to the cube of the height [7]. In order to achieve the desired flexibility for the antenna, the thickness of the substrate needs to be kept at a minimum. 
The initial dimensions of the square patches used in this work were obtained using closed-form equations from [8], [9]. The ELPOSD and SP unit cell were optimized using the same guidelines as in [1], [10].

The SP unit cell can be modeled by a parallel resonant LC circuit as shown in Fig. 2. The impedance between

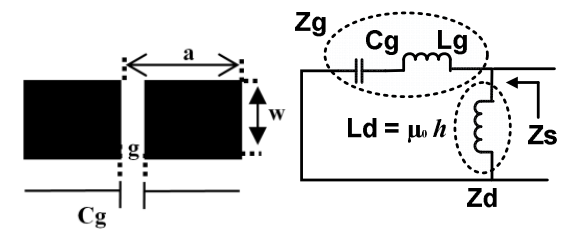
end loading plates Figure 2. Equivalent circuit for the self-resonant is mostly. capacitive grid(left) and series combination of the self-resonant $\left(\mathrm{C}_{\mathrm{g}}\right)$ and is a result grid with the dielectric slab impedance (right) of the charge built

up between these plates [8]. As illustrated in Fig. 2, $Z_{d}$ is inductive $\left(\mathrm{L}_{\mathrm{d}}\right)$. From the parallel LC the circuit equivalent surface impedance is calculated by (1)

$$
\begin{gathered}
Z s=\frac{Z_{g} * Z_{d}}{Z_{g}+Z_{d}} \\
Z s=j \omega L_{d} \frac{1-j \omega^{2} L_{g} C_{g}}{1-\omega^{2}\left(L_{g}+L_{d}\right) C_{g}}
\end{gathered}
$$

The resonant frequency can then be calculated by equating the denominator from (2) to zero, yielding

$$
f_{r}=\frac{1}{2 \pi \sqrt{\left(L_{g}+L_{d}\right) C_{g}}}
$$

The bandwidth is obtained by dividing the equivalent impedance of the FSS by the intrinsic impedance of the superstrate. This equation, derived in detail in [9], gives the bandwidth over which the phase of the reflection coefficient falls between $\pm 45^{\circ}$ :

$$
B W=\frac{\pi \sqrt{\varepsilon_{r}}}{8 \eta_{0}} \sqrt{\frac{L_{g}+L_{d}}{C_{g}}} \times\left(\frac{L_{d}}{L_{g}+L_{d}}\right)^{2}
$$

From (4) the FSS is expected to have more bandwidth when the discrete lumped capacitance decreases, which is supported by the results in Section IV.

\section{MATERIALS AND FABRICATION}

Two dipole antennas (Designs A and B) were designed using Rogers RT6010 substrates, having a vendor-specified dielectric constant of 10.2. A high dielectric constant is preferred for low resonant frequencies to achieve better angular stability and smaller areal dimensions [11]. Design A uses 2.5 $\mathrm{mm}$-thick boards for the electromagnetic band-gap (EBG) and the superstrate that supports the ELPOSD, while Design B uses $1.27 \mathrm{~mm}$-thick boards. The height (h) for each substrate is relatively thick in order to increase the inductance $\left(\mathrm{L}_{\mathrm{d}}\right)$ of the FSS impedance (2). Both antennas were designed and tested with and without the capacitive loading in order to have a useful benchmark for the loaded designs. As illustrated in Fig. 1 , the antennas are fed using a balun that is patterned on the bottom feed layer.

The resulting total antenna thickness for the capacitivelyloaded designs (excluding the feed layer) is $\sim \lambda / 22$ for Design A and $\sim \lambda / 40$ for Design B; this measure includes a $0.8 \mathrm{~mm}$ air gap between the top of the EBG layer and the superstrate, to accommodate the capacitor height. For the unloaded designs, the total thickness values are $\lambda / 25$ and $\lambda / 50$, since there is no air gap.

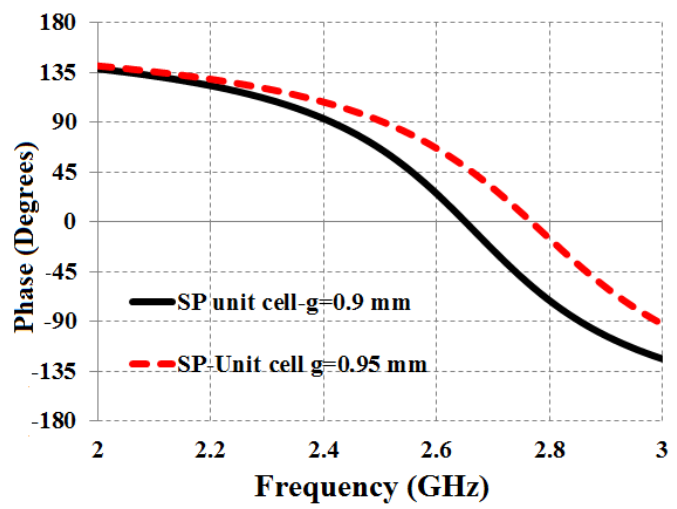

Figure 3. Reflection coefficient phase for a representative SP FSS when the unit cell spacing $(\mathrm{g})$ varies by $0.05 \mathrm{~mm}$.

Chemical etching was used to fabricate the antennas making the best effort to maintain a tight tolerance on the dimensions. This is important as the performance of the FSS is quite sensitive to dimensional variations, especially the spacing between unit cells. This fact is illustrated in Fig. 3, which shows the variation in the phase of the FSS reflection coefficient due to a change in the spacing from $0.9 \mathrm{~mm}$ to 0.95 $\mathrm{mm}$.

\section{Antenna PERformance}

\section{Design A - 2.5 mm-Thick Substrate/Superstrate}

The simulated and measured return loss for the non-loaded Design A antenna are given in Fig. 4. The measured bandwidth around the $2.6 \mathrm{GHz}$ design frequency is $5.3 \%$ and the measured gain is $4.9 \mathrm{~dB}$. This design has a size of $110 \mathrm{~mm} \times 80 \mathrm{~mm}$.

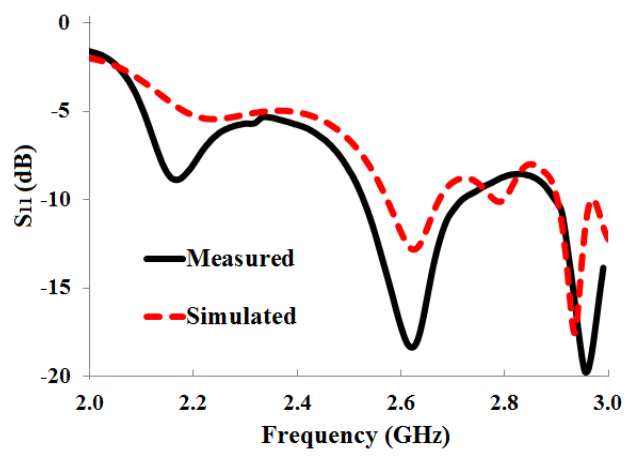

Figure 4. Return loss when Design A is backed by non-loaded FSS.

Introduction of the capacitive-loading produces changes in various dimensions of the antenna. In the case of Design A, the FSS unit cell and overall grid size were changed while the ELPOSD dimensions remained the same. Fig. 5 illustrates the ELPOSD, unit cell and grid, while Fig. 6 compares the FSS grids for the two versions of Design A. The planar size of the loaded grid is $70 \mathrm{~mm} \times 56 \mathrm{~mm}$, which is $55 \%$ smaller than the non-loaded version. This size reduction results primarily from 
the need to use fewer unit cells in the loaded design to achieve comparable return loss characteristics.

The characterization of the loaded FSS unit cell was performed assuming periodic boundary conditions and perfectly matched layers. The reflection coefficient phase for two values of discrete lumped capacitance is shown in Figure 7. The $+/-90^{\circ}$ bandwidth is $\sim 300 \mathrm{MHz}$ and $\sim 500 \mathrm{MHz}$ for 0.7 $\mathrm{pF}$ and $0.3 \mathrm{pF}$ capacitors, respectively. The capacitor values of $0.7 \mathrm{pF}$ and $0.3 \mathrm{pF}$ were selected as these correspond to the capacitance limits within which the varactor diode is tunable.
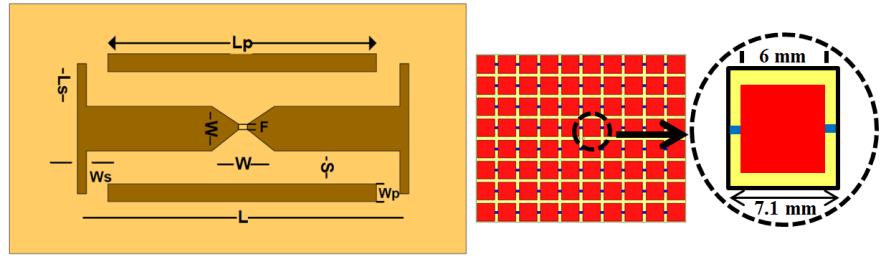

Figure 5. Design A ELPOSD over capacitively-loaded FSS. ELPOSD geometry: $\mathrm{L}=31.5, \mathrm{Lp}=11, \mathrm{Ls}=1.99, \mathrm{~W}=10, \mathrm{Wp}=10, \mathrm{Ws}=2.35, \mathrm{~S}=1 \mathrm{~F}=0.5$ (all in $\mathrm{mm}$ ); Cell Size: $7.1 \mathrm{~mm}$.

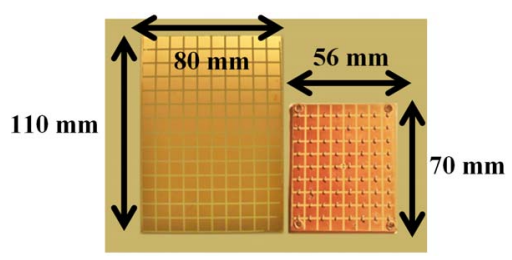

Figure 6. Design A: non-loaded FSS (left) and loaded FSS layer (right).

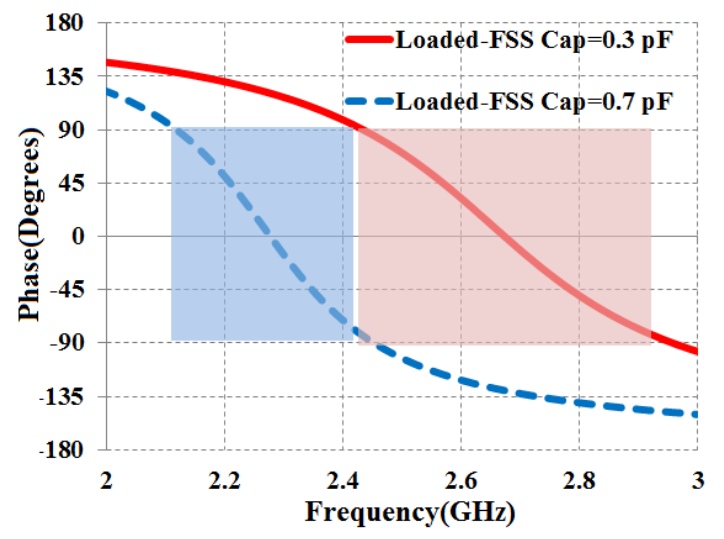

Figure 7. Reflection coefficient phase for a loaded FSS with capacitance values of $0.3 \mathrm{pF}$ and $0.7 \mathrm{pF}$.

The behavior of the antenna return loss when using different capacitance values gives some measure of the potential for a frequency-tunable design. Simulated and measured $\mathrm{S}_{11}$ data for Design A using $0.3 \mathrm{pF}$ and $0.7 \mathrm{pF}$ loading capacitors are shown in Fig. 8. Using the $10 \mathrm{~dB}$ return loss criterion, there is a $670 \mathrm{MHz}$ span between the low end of the response with $0.7 \mathrm{pF}$ capacitors and the high end of the response using $0.3 \mathrm{pF}$ capacitors. This span correlates well with the results in Fig. 7, particularly the $+/-45^{\circ}$ boundaries. Consistent with (3) and (4) it is seen that by increasing the grid capacitance the resonance frequency and bandwidth decrease.
A summary comparison between the non-loaded and loaded versions of Design A is given in Table I. With the $0.3 \mathrm{pF}$ capacitors, the $10 \mathrm{~dB}$ return loss bandwidth is $7.3 \%$ for the simulated and experimental data. Using the $0.7 \mathrm{pF}$ capacitors the simulated bandwidth is $\sim 6.5 \%$; the smaller measured bandwidth of $3.6 \%$ may be the result of tolerances involved with the assembly of the antenna.

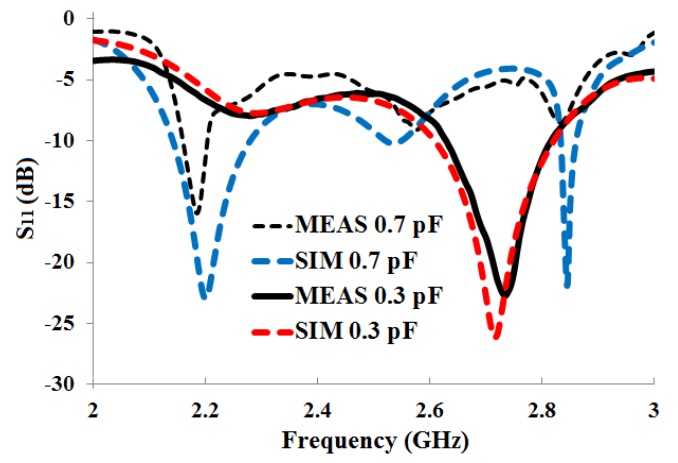

Figure 8. $\mathrm{S}_{11}$ when the Design A ELPOSD is backed by a loaded FSS.

TABLE I. EXPERIMENTAL CHARACTERISTICS OF DESIGN A

\begin{tabular}{|c|c|c|c|c|c|}
\hline $\begin{array}{c}\text { Cap. } \\
\text { Loaded }\end{array}$ & $\begin{array}{c}\text { Cap. } \\
\text { Value } \\
(\boldsymbol{p} \boldsymbol{F})\end{array}$ & $\begin{array}{c}\text { Unit } \\
\text { cells }\end{array}$ & $\begin{array}{c}\text { Planar } \\
\text { Dimensions } \\
(\boldsymbol{m m})\end{array}$ & $\begin{array}{c}\text { BW } \\
(\%)\end{array}$ & $\begin{array}{c}\text { Area } \\
\text { reduction } \\
(\%)\end{array}$ \\
\hline NO & N/A & 140 & $110 \times 80$ & 5.6 & - \\
\hline YES & 0.3 & 72 & $70 \times 56$ & 7.3 & 55 \\
\hline YES & 0.7 & 72 & $70 \times 56$ & 3.6 & 55 \\
\hline
\end{tabular}

\section{Design B - 1.27 mm-Thick Substrate/Superstrate}

A similar comparison as above was performed for Design B without and with capacitive loading. For the non-loaded design the planar size was $120 \mathrm{~mm} \times 90 \mathrm{~mm}$ and the measured fractional bandwidth was 1.6\% (Fig.9). The loaded version was tested using $0.3 \mathrm{pF}$ and $0.7 \mathrm{pF}$ capacitors, with center frequencies of $2.8 \mathrm{GHz}$ and $2.54 \mathrm{GHz}$, respectively. In this case the dimensions of the dipole, unit cell and grid (Fig. 10) were all slightly different from those of the non-loaded design. To maintain comparable return loss characteristics over frequency, equal numbers of unit cells were used for the two versions.

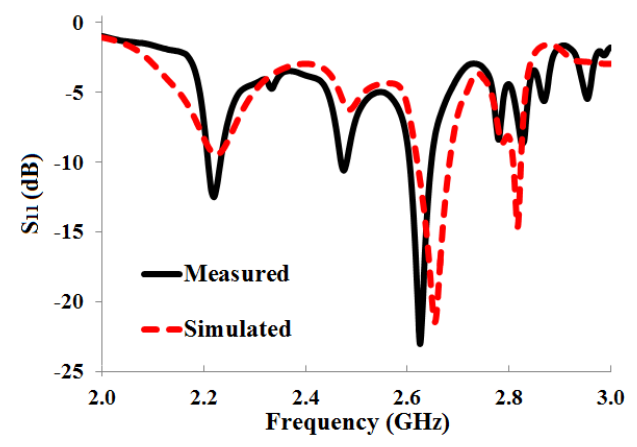

Figure 9. $\mathrm{S}_{11}$ when the Design B ELPOSD is backed by a non-loaded FSS.

The simulated and measured $\mathrm{S}_{11}$ for the two loaded cases are compared in Fig. 11. As before, there is significant tunability in the frequency response using the different 
capacitance values. The measured bandwidths for $0.3 \mathrm{pF}$ and $0.7 \mathrm{pF}$ loading is $9.2 \%$ and $8.4 \%$, respectively. The simulated bandwidth is somewhat smaller in each case, and the discrepancies are suspected to be related to fabrication tolerances. The comparison between the non-loaded and loaded designs is summarized in Table II and Fig. 12.
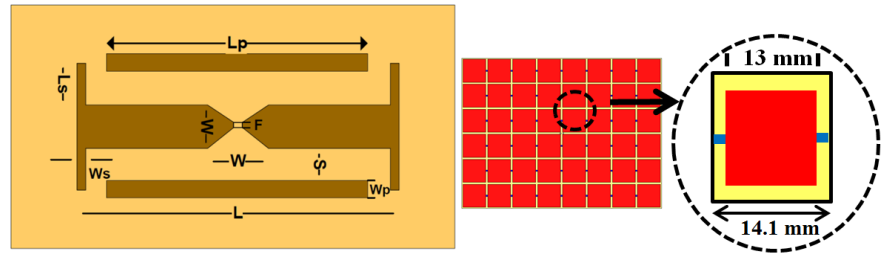

Figure 10. Design B ELPOSD over capacitvely-loaded FSS. ELPOSD geometry $(\mathrm{L}=35, \mathrm{Lp}=11, \mathrm{Ls}=1.99, \mathrm{~W}=10, \mathrm{Wp}=10, \mathrm{Ws}=2.35, \mathrm{~S}=1.5 \mathrm{~F}=0.5$ $(\mathrm{mm}))$. Cell Size $13 \mathrm{~mm}$.

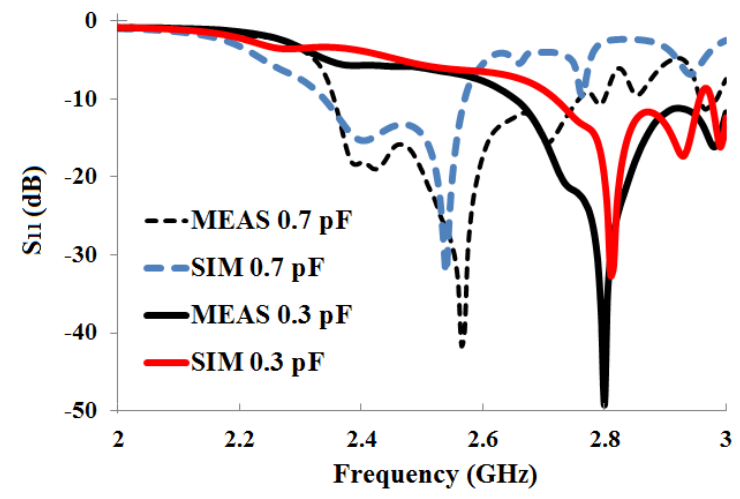

Figure 11. $\mathrm{S}_{11}$ when Design B is backed by a loaded FSS.

TABLE II. EXPERIMENTAL CHARACTERISTICS OF DESIGN B

\begin{tabular}{|c|c|c|c|c|c|}
\hline $\begin{array}{c}\text { Cap. } \\
\text { Loaded }\end{array}$ & $\begin{array}{c}\text { Cap. } \\
\text { Value (pF) }\end{array}$ & $\begin{array}{c}\text { Unit } \\
\text { cells }\end{array}$ & $\begin{array}{c}\text { Planar } \\
\text { Dimensions } \\
(\boldsymbol{m m})\end{array}$ & $\begin{array}{c}\text { BW } \\
(\%)\end{array}$ & $\begin{array}{c}\text { Area } \\
\text { reduction } \\
(\%)\end{array}$ \\
\hline NO & N/A & 48 & $120 \times 90$ & 1.6 & - \\
\hline YES & 0.3 & 48 & $112 \times 85$ & 9.2 & 12 \\
\hline YES & 0.7 & 48 & $112 \times 85$ & 8.4 & 12 \\
\hline
\end{tabular}

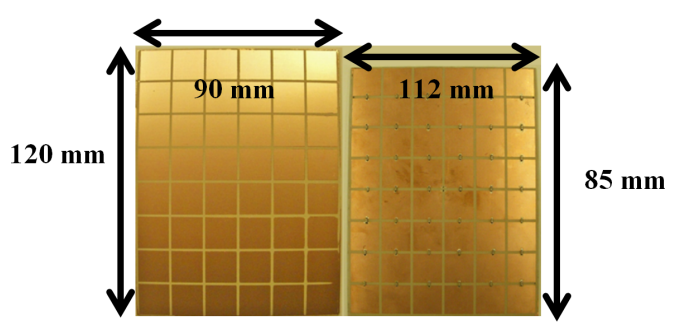

Figure 12. Design B: non-loaded FSS (left) and loaded FSS layer (right).

For completeness, measured E-plane radiation patterns for Design B using $0.7 \mathrm{pF}$ loading capacitors are shown in Fig. 13 at $2.2 \mathrm{GHz}$ and $2.8 \mathrm{GHz}$. The measured gain at the aforementioned frequencies was $4.1 \mathrm{~dB}$ and $3.8 \mathrm{~dB}$, respectively..

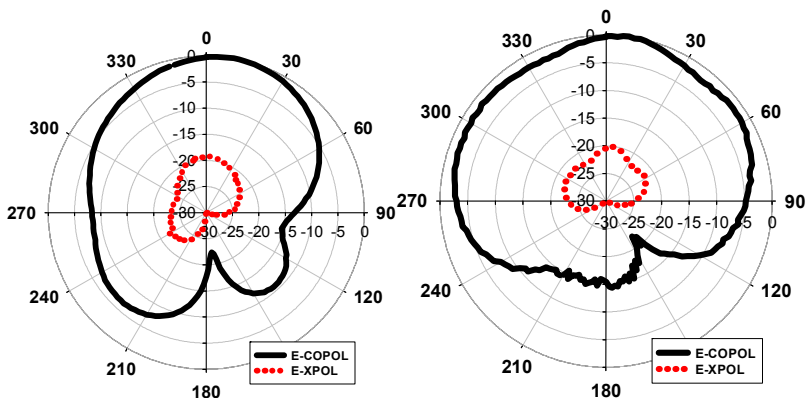

Figure 13. Measured E-plane radiation pattern for Design B using $0.7 \mathrm{pF}$ loading capacitors at $2.2 \mathrm{GHz}$ (left) and $2.8 \mathrm{GHz}$ (right).

\section{CONCLUSION}

The use of 1-D capacitively-loaded frequency selective surfaces with ELPOSD antennas has been presented. Compared with designs that have non-loaded FSS layers, it was shown that increased bandwidth can be achieved and antenna footprints reduced. Furthermore, it is possible to tune the frequency response over $500-700 \mathrm{MHz}$ around $2.5 \mathrm{GHz}$ by varying the value of the loading capacitors. The FSS consisted of square patches without vias, simplifying construction of the antenna and making it more amenable to conformal applications.

\section{ACKNOWLEDGMENT}

The authors thank Rogers Corporation for donating the substrates used in this work.

\section{REFERENCES}

[1] D. Cure, S. Melais, T. Weller, P. Herzig and . Roeder " $2.45 \mathrm{GHz}$ endloaded dipole backed by a high impedance surface," IEEE Antennas Propagation Symposium, Toronto, Canada, July 2010.

[2] M.G. Bray and D.H. Werner, "A Broadband Open-Sleeve Dipole Antenna Mounted Above a Tunable EBG AMC Ground Plane", Antennas and Propagation Society International Symposium, 2004. Volume 2, pp. 1147-1150.

[3] R.E.Collings, Foundations of Microwave Engieering, $2^{\text {nd }}$ ed. New York : McGraw-Hill, 1992.

[4] Hosseini, A. Pirhadi, and M. Hakkak, "Design of an AMC with little sensitivity to angle of incidence using an optimized Jerusalem cross FSS," in Proc. IEEE Int. Workshop Antenna Technol.: Small Antennas Novel Metamat., New York, USA, 2006, pp.245-248.

[5] F. Yang, Y. Rahmat-Samii "Electromagnetic Band Gap (EBG) structures in Antenna Engineering" The Cambridge RF and Microwave Engineering. 2008

[6] K.L Wong, "Compact and Broadband Microstrip Antennas", Wiley, New York, 2002

[7] J. M. Gere and S. P. Timoshenko, Mechanics of Materials, $4^{\text {th }}$ ed. PWS Pub. Co.; May 1997.

[8] D. Sievenpiper, "High-impedance electromagnetic surfaces," Ph.D. dissertation, Dept. Elect. Eng., Univ. California at Los Angeles, Los Angeles, CA, 1999

[9] M. Hosseini and M. Hakkak, "Characteristic estimation for Jerusalem Cross Based artificial magnetic conductors," IEEE Antennas and Wireless Propag. Letters, Vol. 7, 2008.

[10] Werner D.H and Spence T.G "A Novel Miniature Broadband/Multiband Antenna Based on an End-Loaded Planar Open-Sleeve Dipole" IEEE Trans. Antennas Propag., vol. 54, no. 12, pp.3014-3020, Dec. 2006. M.

[11] C.R. Simovski, P. de Maagt, S.A. Tetryakov, M. Paquay, and A. A. Sochava, "Angular stabilization of resonant frequency of artificial magnetic conductors for TE-incidence," Electron. Lett., vol.40, no. 2, pp. 92-93, 2004 